\title{
Correction to: Down-Regulation of microRNA-30d Alleviates Intervertebral Disc Degeneration Through the Promotion of FOXO3 and Suppression of CXCL10
}

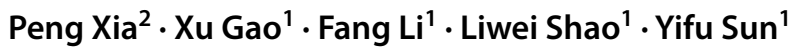

Accepted: 10 December 2021 / Published online: 4 February 2022

(c) Springer Science+Business Media, LLC, part of Springer Nature 2021

\section{Correction to: \\ Calcified Tissue International (2021) 108:252-264 \\ https://doi.org/10.1007/s00223-020-00760-w}

In this article [1], the affiliation details for Yifu Sun were incorrectly given as 'Second Hospital of Jilin University' but should have been 'The Third Hospital of Jilin University'. The affiliation has been corrected with this correction.

Publisher's Note Springer Nature remains neutral with regard to jurisdictional claims in published maps and institutional affiliations.

The original article can be found online at https://doi.org/10.1007/ s00223-020-00760-w.

Yifu Sun

yifu@jlu.edu.cn

1 Department of Orthopedics, The Third Hospital of Jilin University, Changchun 130033, Jilin Province,

People's Republic of China

2 Department of Orthopedics, Second Hospital of Jilin University, Changchun 130012, Jilin Province,

People's Republic of China 